\title{
Condensation in a square minichannel: application of the VOF method
}

\author{
Enrico DA RIVA, Stefano BORTOLIN, Davide DEL COL * \\ * Corresponding author: Tel.: +39049 8276891; Fax: +39 049 8276896; \\ Email: davide.delcol@unipd.it \\ Dipartimento di Fisica Tecnica, Università di Padova, Italy
}

\begin{abstract}
A number of steady-state simulations of condensation of R134a at mass fluxes $G=100 \mathrm{~kg} \mathrm{~m}^{-2} \mathrm{~s}^{-1}$ and $G=800 \mathrm{~kg} \mathrm{~m}^{-2} \mathrm{~s}^{-1}$ inside a square cross section minichannel $\left(D_{h}=1 \mathrm{~mm}\right)$ are here proposed and compared against similar simulations in a circular cross section channel with same diameter. The VOF (Volume Of Fluid) method is used to track the vapour-liquid interface and the effects of interfacial shear stress and surface tension are both taken into account. A uniform wall temperature is fixed as boundary condition.

At $G=100 \mathrm{~kg} \mathrm{~m}^{-2} \mathrm{~s}^{-1}$ the liquid film is assumed laminar and the vapour flow is turbulent; turbulence is handled by a low-Reynolds number form of the standard $k$ - $\omega$ model (Wilcox, 1998), which was modified in order to suppress the turbulent viscosity inside the liquid phase. At $G=800 \mathrm{~kg} \mathrm{~m}^{-2} \mathrm{~s}^{-1}$ a low-Re form of the SST $k$ - $\omega$ model (Menter, 1994) has been used for turbulence modeling through both the liquid and vapour phases. Numerical simulations are validated against experimental data.

The present paper looks at the effect of surface tension. Its influence on the shape of the vapour-liquid interface provides some heat transfer enhancement in non-circular minichannels. In circular minichannels, the overall effect of surface tension is shown to be not significant. On the contrary, the effect of surface tension in square channels provides a large enhancement at low mass flux.
\end{abstract}

Keywords: minichannel, condensation, VOF method

\section{Introduction}

A more complete understanding and theoretical modeling of the two-phase flow and heat transfer process in minichannels is needed for the design and optimization of heat exchangers.

A number of different methods are currently available for the direct simulation of multiphase flows. These techniques can be very useful, in particular when trying to extend the investigation to new minichannel geometries. Simulations are presented in this paper using the Volume of Fluid (VOF) method which can handle multiphase flows of immiscible fluids, tracking the motion of the interface between them without using empirical closure laws to model the interaction between the phases. The capability of this method to take into account the surface tension force, in particular, is very promising, since the effect of surface tension is expected to be important at small scales and when using non- circular minichannel shapes.

During condensation inside minichannels, the surface tension is supposed to enhance the heat transfer in the presence of corners as compared to the case of circular channels, because the liquid is pulled towards the corners leading to a thinner liquid film at the flat sides and therefore to a local lower thermal resistance. This may provide a higher average heat transfer coefficient on the perimeter of the channel. Besides, this subject is particularly interesting since most of the mini and microchannels used in practical applications have non circular cross sections.

A theoretical study of film condensation in minichannels, taking into account surface tension, gravity and vapour shear stress was reported in Wang and Rose (2006). In their work, the condensate film is treated assuming laminar flow and neglecting inertia and convection terms. They covered the square section channel but the simulations and the basic assumptions were not experimentally 
validated.

One should note that, in the literature, the number of local heat transfer coefficient data measured during condensation inside a single minichannel is rather limited. So far, very few attempts to measure the local heat transfer coefficient in square or rectangular cross section single minichannels have been performed. In this work some data points taken by Del Col et al. (2011) will be used to validate the simulation results.

In particular, the present work will look at the effect of surface tension. Its influence on the vapour-liquid interface may provide some heat transfer enhancement in non-circular minichannels.

Table 1: Simulations cases reported in this paper (R134a, $D_{h}=1 \mathrm{~mm}$, inlet vapour quality $x=1$, saturation temperature $t_{S}=40^{\circ} \mathrm{C}$, wall temperature $t_{W}=30^{\circ} \mathrm{C}$ ).

\begin{tabular}{|c|c|c|c|c|}
\hline \multirow{2}{*}{\multicolumn{2}{|c|}{ 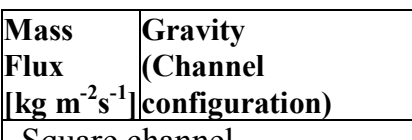 }} & \multirow[t]{2}{*}{\begin{tabular}{|l|} 
Surface \\
tension
\end{tabular}} & \multicolumn{2}{|c|}{\begin{tabular}{|l|l|}
$\begin{array}{l}\text { Channel } \\
\text { length }\end{array}$ & $\begin{array}{l}\text { qutlet } \\
\text { quality }\end{array}$ \\
{$[\mathrm{mm}]$} & {$[-]$} \\
\end{tabular}} \\
\hline & & & \multicolumn{2}{|c|}{ Square channel } \\
\hline 100 & NO & YES & 50 & 0.58 \\
\hline 100 & $\mathrm{NO}$ & $\mathrm{NO}$ & 100 & 0.54 \\
\hline 800 & $\mathrm{NO}$ & YES & 150 & 0.43 \\
\hline 800 & $\mathrm{NO}$ & $\mathrm{NO}$ & 150 & 0.47 \\
\hline \multicolumn{5}{|c|}{ Circular channel } \\
\hline 100 & $\mathrm{NO}$ & YES & 125 & 0.41 \\
\hline 800 & $\mathrm{NO}$ & YES & 150 & 0.44 \\
\hline 100 & YES (Horizontal) & YES & 75 & 0.46 \\
\hline 100 & YES (Horizontal) & $\mathrm{NO}$ & 75 & 0.45 \\
\hline 100 & YES (Vertical) & YES & 125 & 0.39 \\
\hline 800 & YES (Horizontal) & YES & 150 & 0.43 \\
\hline 800 & YES (Horizontal) & $\mathrm{NO}$ & 150 & 0.43 \\
\hline 800 & YES (Vertical) & YES & 150 & 0.44 \\
\hline
\end{tabular}

\section{Numerical simulations}

A number of steady-state simulations of condensation of R134a at mass fluxes $G=100$ $\mathrm{kg} \mathrm{m}^{-2} \mathrm{~s}^{-1}$ and $G=800 \mathrm{~kg} \mathrm{~m}^{-2} \mathrm{~s}^{-1}$ inside a square cross section minichannel $\left(D_{h}=1 \mathrm{~mm}\right)$ are here proposed and compared against similar simulations in a circular cross section channel with the same diameter. The inlet thermodynamic vapour quality is $x=1$. The effect of surface tension has been taken into account. The effect of gravity has been considered only in the circular channel. The simulations have been performed by means of the VOF method implemented in the commercial code ANSYS FLUENT 13.

The minichannel wall is isothermal and a uniform temperature $t_{W}=30^{\circ} \mathrm{C}$ was fixed as boundary condition, while the saturation temperature of the fluid was $t_{S}=40^{\circ} \mathrm{C}$. In the Cartesian axis convention used in the present paper, the $z$-axis corresponds to the axial axis of the channel. Details about the mass flux, channel length, outlet vapour quality, treatment of gravity and surface tension are reported in Table 1 for each case.

It must be noticed that, since steady-state simulations are performed, intermittent flows such as plug/slug flows cannot be predicted by the present numerical model. A flow pattern map for R134a in a $1 \mathrm{~mm}$ i.d. pipe has been developed from experimental visualizations at $52^{\circ} \mathrm{C}$ by Coleman and Garimella (2000). According to their results, the flow pattern is expected to be "annular film flow" or "annular film and mist flow" for most of the channel length at the conditions considered in Table 1, "mist flow" is expected for $x>0.7$ at $G=800$ $\mathrm{kg} \mathrm{m}^{-2} \mathrm{~s}^{-1}$ and "plug/slug and annular film flow" is expected for $x<0.8$ at $G=100 \mathrm{~kg} \mathrm{~m}^{-}$ ${ }^{2} \mathrm{~S}^{-1}$.

Regarding the circular minichannel, a mesh with around $1.15 \cdot 10^{6}$ hexahedrons cells has been used for three-dimensional simulations. In order to fully resolve the liquid film region, the radial thickness of the cells in the near-wall region is around $0.8 \mu \mathrm{m}$, while the mesh is much coarser in the core region. 450 nodes are used for the axial discretization, and the mesh was scaled in the axial direction for each case according to the required tube length.

In the case of the square minichannel, the domain is discretized into $1.94 \cdot 10^{6}$ hexahedrons cells; the radial thickness of the cells in the near-wall region is around $1 \mu \mathrm{m}$, while the mesh is much coarser in the core region; 385 nodes are used for the axial discretization.

Some single-phase simulations have been performed using a $1 \mathrm{~m}$ long (i.e. 1000 times the hydraulic diameter) mesh, in order to obtain the fully developed turbulent solution for the vapour flow. Such results have been used to set the inlet boundary conditions for 
the $z$-velocity, the turbulent kinetic energy and the turbulent specific dissipation rate.

\subsection{VOF Method}

The VOF method is able to compute multiphase flows of immiscible fluids tracking the motion of the interface between them. A scalar field called "volume fraction" (i.e. $\alpha$ ) and representing the portion of the volume of the computational cell filled with one phase is used.

The VOF algorithm is divided into two parts: a reconstruction step and a propagation step. The problem of interface reconstruction is that of finding an approximation to the section of the interface in each cut cell, by knowing the volume fraction in that cell and in the neighbouring ones. Once the interface has been reconstructed, its motion by the underlying flow field is modeled by an advection algorithm.

The two-phase mixture is considered in the VOF method as a single fluid with properties changing depending on the value of the volume fraction $\alpha$. Properties (viscosity, density, thermal conductivity) are computed for each cell by means of an arithmetic mean:

$$
\varphi=\varphi_{L} \alpha_{L}+\varphi_{G}\left(1-\alpha_{L}\right)
$$

where $\varphi$ is a property of the two-phase mixture.

All properties have been considered temperature dependent and computed from the REFPROP8 database (NIST, 2007).

The following continuity equations are solved:

$$
\begin{aligned}
& \nabla \cdot\left(\vec{u} \alpha_{L}\right)=\frac{S}{\rho_{L}} \\
& \nabla \cdot\left(\vec{u} \alpha_{G}\right)=-\frac{S}{\rho_{G}}
\end{aligned}
$$

where $S$ is the mass source term due to phase change.

The usual Navier-Stokes equations are used for the momentum in the cells where only one of the two phases is present. At the interface (i.e. $0<\alpha_{L}<1$ ), instead, the force due to the surface tension $F_{\sigma}$ must be taken into account:

$$
\nabla \cdot(\rho \vec{u} \vec{u})=-\nabla p+\nabla \cdot\left[\left(\mu+\mu_{t}\right)\left(\nabla \vec{u}+\nabla \vec{u}^{T}\right)\right]+\rho \vec{g}+\vec{F}_{\sigma}
$$

The effect of surface tension is written in terms of a pressure jump across the interface. The volume force due to the surface tension is computed by means of the CSF (Continuum Surface Force) model proposed by Brackbill et al. (1992), as follows:

$$
\begin{aligned}
& \kappa_{L}=\nabla \cdot \frac{\nabla \alpha_{L}}{\left|\nabla \alpha_{L}\right|} \\
& \vec{F}_{\sigma}=\sigma_{L G} \frac{\rho \kappa_{L} \nabla \alpha_{L}}{0.5\left(\rho_{L}+\rho_{G}\right)}
\end{aligned}
$$

where $\kappa_{L}$ is the surface curvature and $\sigma_{L G}$ is the surface tension.

All the scalar values are shared by the phases throughout the domain, therefore no particular issues for the treatment of energy or turbulence equations arise.

The following energy equation is solved:

$$
\nabla \cdot(\vec{u} \rho h)=\nabla \cdot\left(\lambda_{\text {eff }} \nabla T\right)+h_{L V} S
$$

where $\lambda_{\text {eff }}$ is the effective thermal conductivity, $h$ is the specific enthalpy and the last term $\left(h_{L V}\right.$ $S$ ) is the energy source due to phase change.

The Green-Gauss node-based method has been used for gradients evaluation. The implicit scheme was used for time discretization, and the modified High Resolution Interface Capturing (HRIC) scheme (Muzaferija et al., 1998) was used for VOF calculations. The PRESTO! scheme was used for the pressure interpolation, while the pressure-velocity coupling was handled by means of the SIMPLE algorithm. The third order MUSCL scheme (Val Leer, 1979) was used for the momentum equation, the two turbulence equations and the energy equation.

\subsection{Turbulence modeling}

The all-liquid Reynols number is $\mathrm{Re}_{\mathrm{LO}}$ $=G D_{h} / \mu_{L}=619$ and $\operatorname{Re}_{\mathrm{LO}}=4955$ at $G=100 \mathrm{~kg}$ $\mathrm{m}^{-2} \mathrm{~s}^{-1}$ and $\mathrm{G}=800 \mathrm{~kg} \mathrm{~m}^{-2} \mathrm{~s}^{-1}$, respectively, while the corresponding all-vapour Reynols number are $\operatorname{Re}_{\mathrm{GO}}=G D_{h} / \mu_{G}=8082$ and $\operatorname{Re}_{\mathrm{GO}}$ $=64657$. The vapour flow can therefore be 
considered turbulent, while no a priori assumption can be made for the liquid flow, since, depending on the mass flux and the position along the minichannel, both turbulent and laminar flows are expected to occur in the condensate film (the local liquid film thickness and velocity vary both in the axial direction and along the channel perimeter). For this reason, two different computational approaches have been considered. The first approach (referred to as laminar liquid film in the paper) corresponds to the assumption that the flow is laminar inside the liquid phase and turbulent inside the vapour phase. For the second approach (referred to as turbulent liquid film in the paper), instead, a low Reynolds form of a turbulence model has been used through the whole computational domain.

Laminar liquid film approach. This computational approach is used for the simulations at $G=100 \mathrm{~kg} \mathrm{~m}^{-2} \mathrm{~s}^{-1}$ since it has been previously validated against experimental data, displaying a good agreement at this mass flux value (Da Riva and Del Col, 2011). Turbulence is handled by a modified lowReynolds form of the $k-\omega$ model by Wilcox (1998). A modified equation is used for the computation of the turbulent viscosity $\mu_{T}$ : the standard low-Re formulation by Wilcox (1998) is retained for the vapour phase, while $\mu_{T}$ is set to be null in the liquid phase and blended between the two values at the interface; in this way, inside the liquid phase the laminar flow is imposed and the turbulence production is suppressed. The present computational approach is described in detail in Da Riva and Del Col (2011).

Turbulent liquid film approach. This computational approach is used for the simulations at $G=800 \mathrm{~kg} \mathrm{~m}^{-2} \mathrm{~s}^{-1}$ since it has been previously validated against experimental data, displaying a good agreement at this mass flux value (Da Riva et al., 2010). A low Reynolds form of the SST $k-\omega$ model by Menter (1994) has been used for turbulence modelling through the entire computational domain. A detailed description of this computational approach and a comparison with the laminar liquid film approach is reported in (Da Riva et al., 2010).

\subsection{Phase Change Modelling}

At the operating conditions considered in the present simulations, the molecular kinetic thermal resistance at the interface is negligible and the interfacial temperature can be assumed to be equal to the saturation temperature.

The numerical technique described by the following equations (Lee, 1980) has been employed in the simulations in order to model the phase-change process:

$$
\begin{array}{ll}
S=-r \alpha_{L} \rho_{L} \frac{T-T_{S}}{T_{S}} & T \geq T_{S} \\
S=r \alpha_{G} \rho_{G} \frac{T_{S}-T}{T_{S}} & T<T_{S}
\end{array}
$$

where $S$ is the source term in the continuity equations (2) and (3) and in the energy equation (7), $T$ is the cell temperature and $r$ is a positive numerical coefficient.

If at some step of the computation the temperature of a cell in the domain is higher than the saturation temperature, the first of the two equations is used: if this cell belongs to the vapour phase (i.e. $\alpha_{L}=0$ ) no mass transfer is computed; if this cell belongs to the liquid phase (i.e. $\alpha_{L}>0$ ), mass transfer from the liquid to the vapour phase is computed. Besides, the temperature of the cell is decreased by the source term due to phase change in the energy equation (7). The computation is analogous for the cells with temperature lower than the saturation one. In this way, the presence of cells in the vapour phase with temperature lower than the saturation temperature, as well as the presence of cells in the liquid phase with temperature higher than the saturation temperature is avoided. The source term $S$ in Eq. (8) is arbitrary fixed; however, mass, momentum and energy are conserved at every computational step.

At convergence, the interface should reach the saturation temperature, while all the cells belonging to the liquid phase should reach a lower temperature and all the cells belonging to the vapour a higher temperature. 


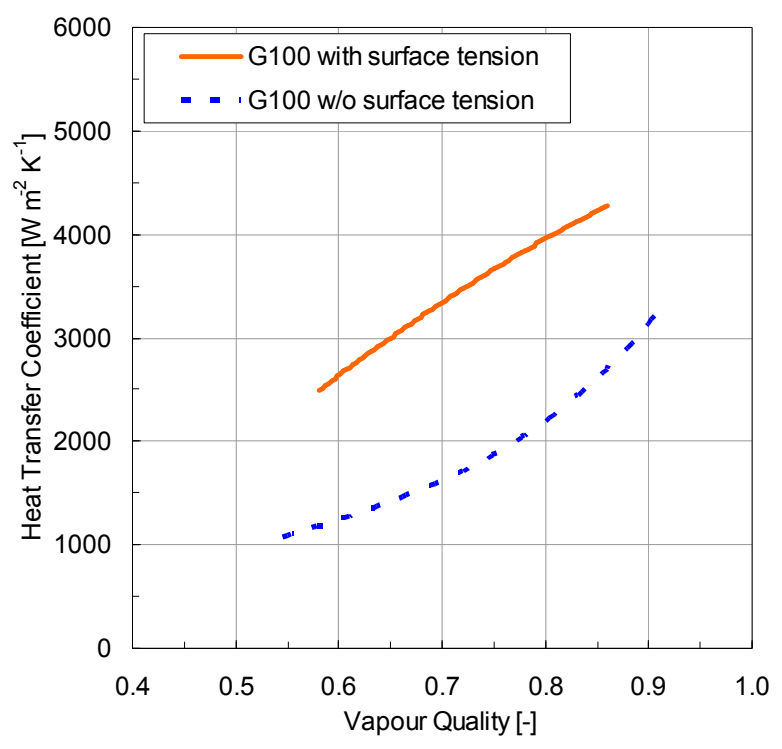

Figure 1. Heat transfer coefficient in the square channel at $G=100 \mathrm{~kg} \mathrm{~m}^{-2} \mathrm{~s}^{-1}$ and zero gravity.

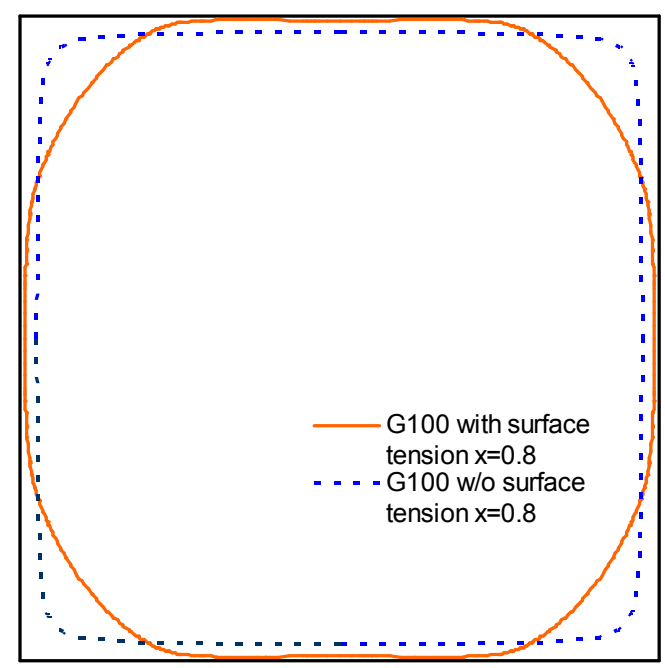

Figure 2. Interface in minichannel cross section at $x=0.8, G=100 \mathrm{~kg} \mathrm{~m}^{-2} \mathrm{~s}^{-1}$ and zero gravity: effect of surface tension.

In practice, the interfacial temperature obtained by the use of this numerical technique will not be exactly the saturation temperature. Excessively small values of the coefficient $r$ lead to a significant deviation between interfacial and saturation temperature. Furthermore, when higher values of the coefficient $r$ are used, the interface (i.e. the region of cells with $\left.0<\alpha_{L}<1\right)$ is sharper and thinner. However, too large values of $r$ cause numerical convergence problems and optimal values must be found for each case. In the present simulations, the coefficient $r$ ranged from $7.510^{5}$ up to $10^{7}$ and the deviation between interface and saturation temperatures ranges from $0.5 \mathrm{~K}$ to $1.5 \mathrm{~K}$.

\section{Results and discussion}

\subsection{Results at low mass flux}

Condensation in square minichannel has been investigated under zero-gravity condition. In this case the problem has two symmetry planes, with much less computational effort. Nevertheless, the effect of gravity will be discussed from some simulations performed in the circular channel.

In the simulations of condensation at $G=100$ $\mathrm{kg} \mathrm{m}^{-2} \mathrm{~s}^{-1}$ the flow is treated as laminar inside the entire liquid film and turbulent inside the vapour phase by adopting a modified low-Re $k-\omega$ model (Da Riva et al., 2010) for the turbulence modelling.

It must be noticed that the assumption of laminar liquid film is usual among the theoretical models to predict film condensation available in the literature (e.g. Wang and Rose, 2006, Nebuloni and Thome, 2010).

Numerical results of cross sectional average heat transfer coefficients during condensation inside a square minichannel under zero-gravity at $G=100 \mathrm{~kg} \mathrm{~m}^{-2} \mathrm{~s}^{-1}$ are plotted versus vapour quality in Fig. 1. The heat transfer coefficient decreases monotonically for vapour quality ranges between 0.9 and 0.55 . Simulations have been run at two different conditions: with surface tension and without taking into account surface tension. As it can be seen in Fig. 1, the surface tension enhances the heat transfer coefficient; the reason for this behavior can be seen in Fig. 2 where the interface at vapour quality $x=0.8$ is reported. The liquid is pulled towards the corners leading to a thinner liquid film on the flat sides and therefore to a lower local thermal resistance. This provides a higher average heat transfer coefficient on the perimeter of the channel.

Although the influence of the surface tension can be seen from the shape of the vapourliquid interface also in circular minichannels (Fig. 4), the overall effect of surface tension, 
in this case, is shown to be small, since the global heat transfer rate computed neglecting the effect of surface tension, during condensation from 1 to 0.5 vapour quality, is almost the same as the value computed considering surface tension. This can also be seen in Fig. 3 where the effect of surface tension is shown to be negligible at normal gravity and null at zero gravity. The influence of gravity during condensation in a circular minichannel is discussed in more details in Da Riva and Del Col (2011b).

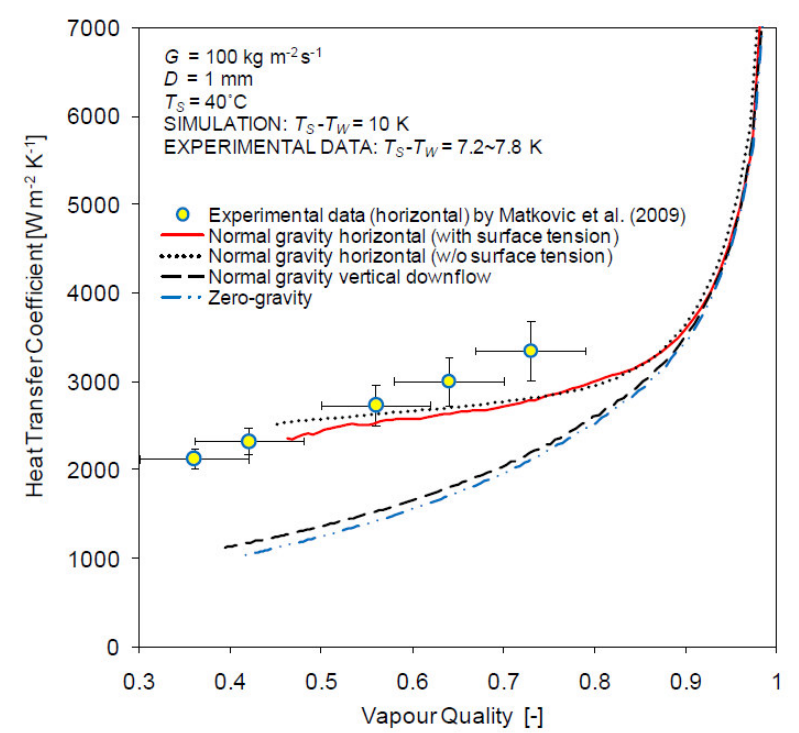

Figure 3. Cross sectional average heat transfer coefficient versus vapour quality at $G=100 \mathrm{~kg}$ $\mathrm{m}^{-2} \mathrm{~s}^{-1}$ in a circular minichannel.

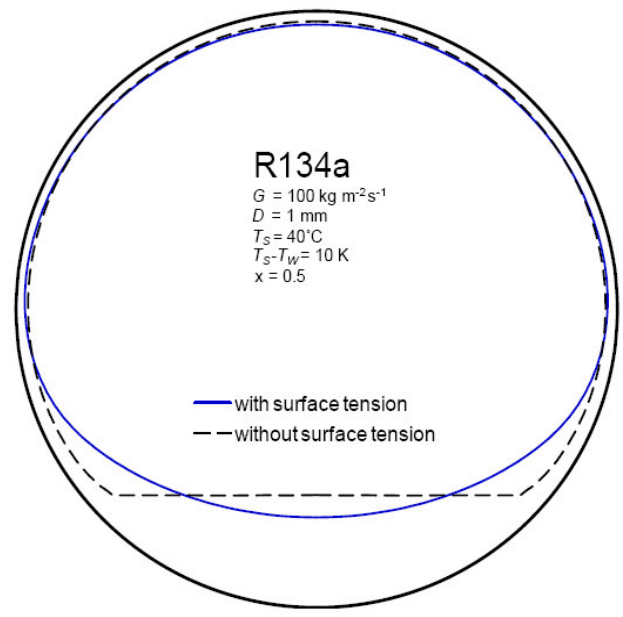

Figure 4. Interface at cross section corresponding to 0.5 vapour quality for simulations with and without surface tension in circular $1 \mathrm{~mm}$ diameter channel.
In Fig. 3 the numerical results obtained during condensation inside a circular minichannel at $G=100 \mathrm{~kg} \mathrm{~m}^{-2} \mathrm{~s}^{-1}$ under normal gravity and horizontal configuration are validated against experimental data by Matkovic et al. (2009). This data was measured at normal gravity conditions inside a $0.96 \mathrm{~mm}$ circular minichannel at $40^{\circ} \mathrm{C}$ saturation temperature. As one can see in Fig. 3 , the computed heat transfer coefficient is in good agreement with the experimental data.

\subsection{Results at high mass flux}

In the simulations at high mass flux, a low Reynolds form of the SST $k-\omega$ model (Menter, 1994) has been used for turbulence modeling through the entire computational domain without any modification.

Numerical results of cross sectional average heat transfer coefficients during condensation inside a square minichannel under zero-gravity at $G=800 \mathrm{~kg} \mathrm{~m}^{-2} \mathrm{~s}^{-1}$ are plotted versus vapour quality in Fig. 5.

Although the influence of the surface tension can be seen from the shape of the vapourliquid interface (Fig. 6), the overall effect of surface tension on the heat transfer coefficient, in this case, is shown to be small.

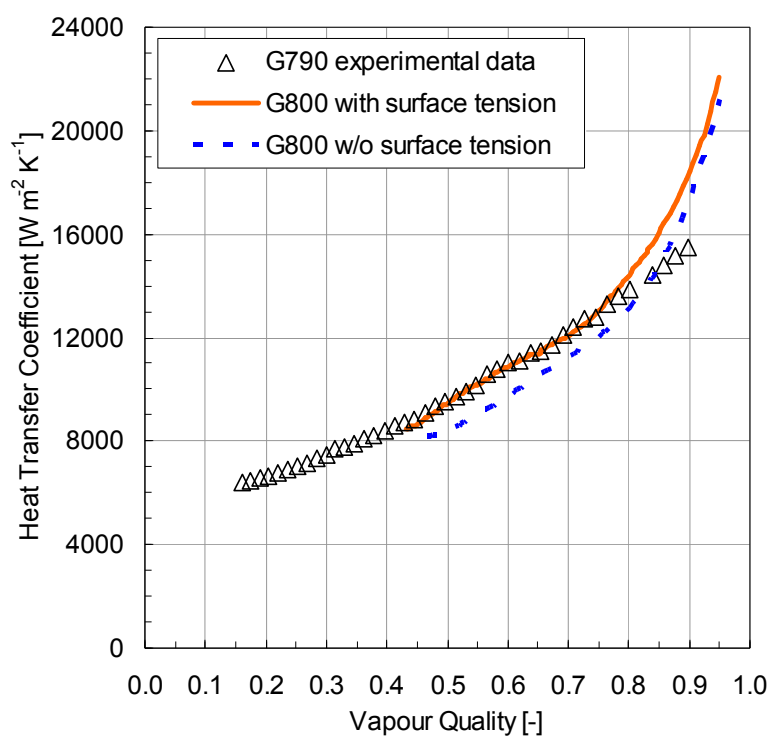

Figure 5. Heat transfer coefficient as a function of vapour quality in a square minichannel. Simulations with turbulent film approach and experimental data from Del Col et al. (2011). 


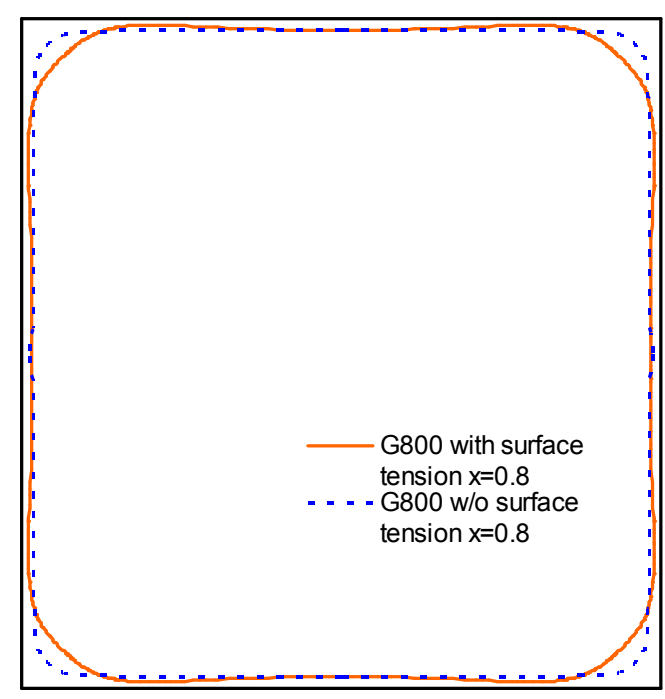

Figure 6. Interface in minichannel cross section at $x=0.8, G=800 \mathrm{~kg} \mathrm{~m}^{-2} \mathrm{~s}^{-1}$ and zero gravity: effect of surface tension.

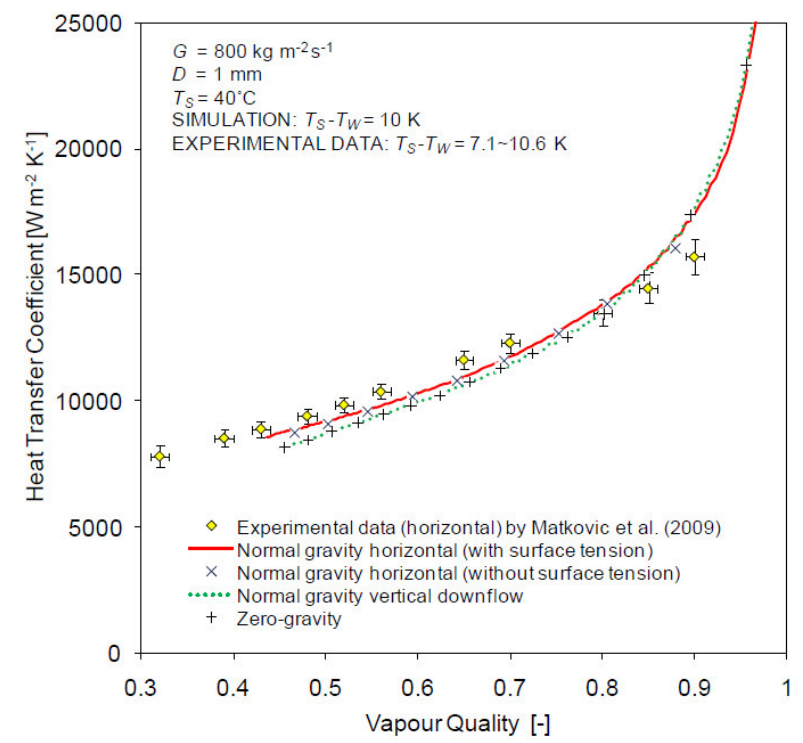

Figure 7. Cross sectional average heat transfer coefficient versus vapour quality at $G=800 \mathrm{~kg}$ $\mathrm{m}^{-2} \mathrm{~s}^{-1}$ in a circular minichannel.

Since at high mass velocities condensation is shear stress dominated and gravity has a minor effect in the circular channel (Fig. 7), neither in the square minichannel gravity is expected to play an important role at $G=800 \mathrm{~kg} \mathrm{~m}^{-2} \mathrm{~s}^{-1}$. With this assumption, numerical results obtained during condensation inside square minichannel at $G=800 \mathrm{~kg} \mathrm{~m}^{-2} \mathrm{~s}^{-1}$ under zerogravity are validated against experimental data by Del Col et al. (2011). This data was measured at normal gravity conditions inside a square minichannel having a hydraulic diameter of $1.23 \mathrm{~mm}$. As one can see in Fig. 5, the computed heat transfer coefficient is in good agreement with the experimental results.

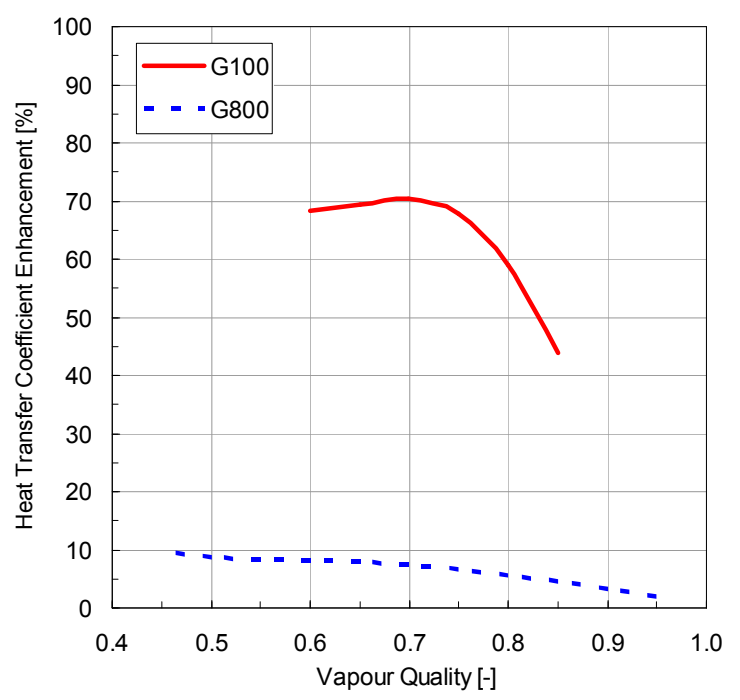

Figure 8. Heat transfer enhancement at $G=$ $100 \mathrm{~kg} \mathrm{~m}^{-2} \mathrm{~s}^{-1}$ and $\mathrm{G}=800 \mathrm{~kg} \mathrm{~m}^{-2} \mathrm{~s}^{-1}$ in the square channel as compared to the circular channel, at zero gravity.

\subsection{Comparison between square and circular minichannel}

A comparison between heat transfer coefficients calculated inside the square and the circular minichannel under zero-gravity is illustrated in Fig 8. The heat transfer coefficient enhancement in the square channel with respect to the circular minichannel is reported on the $y$-axis. At high mass velocity the channel shape does not affect the heat transfer. At low mass velocity a significant enhancement of the heat transfer coefficient is found in the square channel due to the surface tension effect.

\section{Conclusions}

Numerical simulations of R134a condensation are performed in a square and in a circular minichannel with the same hydraulic diameter $\left(D_{h}=1 \mathrm{~mm}\right)$. The effects of surface tension and channel geometry have been discussed at two different mass velocities.

Surface tension was found to have an important role in the square minichannel at low mass velocity. At high mass velocity 
where the interfacial shear stress is the prevailing force, the surface tension has a minor effect on the heat transfer coefficient.

In this paper the gravity effect is not considered in the square channel (results are available for the circular channel) to reduce the computational time. Future work will be performed to study the contemporary effects of surface tension and gravity in the square shape, both numerically and experimentally.

\section{Nomenclature}

$\begin{array}{ll}D_{h} & \text { hydraulic diameter }(\mathrm{m}) \\ g & \text { gravity acceleration }\left(\mathrm{kg} \mathrm{m} \mathrm{s}^{-2}\right) \\ G & \text { mass flux }\left(\mathrm{kg} \mathrm{m}^{-2} \mathrm{~s}^{-1}\right) \\ h & \text { specific sensible enthalpy }\left(\mathrm{J} \mathrm{kg}^{-1}\right) \\ h_{L V} & \text { latent heat }\left(\mathrm{J} \mathrm{kg}^{-1}\right) \\ S & \text { phase change mass source }\left(\mathrm{kg} \mathrm{m}^{-3} \mathrm{~s}^{-1}\right) \\ t & \text { temperature }\left({ }^{\circ} \mathrm{C}\right) \\ T & \text { temperature }(\mathrm{K}) \\ u & \text { velocity }\left(\mathrm{m} \mathrm{s}^{-1}\right) \\ x & \text { thermodynamic vapour quality }(-) \\ \text { Greek } & \text { letters } \\ \alpha & \text { volume fraction }(-) \\ \kappa_{L} & \text { interface curvature }\left(\mathrm{m}^{-1}\right) \\ \lambda & \text { thermal conductivity }\left(\mathrm{Wm}^{-1} \mathrm{~K}^{-1}\right) \\ \mu & \text { dynamic viscosity }\left(\mathrm{Pa} \mathrm{s}^{-1}\right) \\ \rho & \text { density }\left(\mathrm{kg} \mathrm{m} \mathrm{m}^{-3}\right) \\ \sigma & \text { surface tension }\left(\mathrm{N} \mathrm{m} \mathrm{m}^{-1}\right) \\ \text { Subscripts } \\ \mathrm{G} & \text { gas/vapour phase } \\ \mathrm{L} & \text { liquid phase } \\ \mathrm{S} & \text { saturation } \\ \mathrm{t} & \text { turbulent } \\ \mathrm{W} & \text { wall }\end{array}$

\section{References}

Brackbill, J.U., Kothe D. B., Zemach, C., 1992, A Continuum Method for Modeling Surface Tension. J. Comput. Phys. 100, 335354.

Coleman, J.W., Garimella, S., 2000, Twophase flow regime transitions in microchannel tubes: the effect of hydraulic diameter, Orlando, FL: American Society of Mechanical Engineers, Heat Transfer Division, 71-83.

Da Riva, E., Del Col, D., Cavallini, A., Garimella, S.V., 2010, Simulation of condensation in a circular minichannel: Application of the VOF method and turbulence model, International Refrigeration and Air Conditioning Conference, July 12-15, 2010, Purdue, West Lafayette, IN, USA.

Da Riva, E., Del Col, D., 2011, Numerical simulation of laminar liquid film condensation in a horizontal circular minichannel, ASME J. Heat Transfer (accepted).

Da Riva, E., Del Col, D., 2011b, Effect of Gravity during Condensation of R134a in a Circular Minichannel, Microgravity Sci. Technol. (accepted).

Del Col D., Bortolin S., Cavallini A., Matkovic M., 2011, Effect of cross sectional shape during condensation in a single square minichannel, IJHMT, vol.54, 3909-3920.

Lee, W.H., 1980, A pressure iteration scheme for two-phase flow modeling, in: T.N. Veziroglu (Ed.), Multiphase Transport Fundamentals, Reactor Safety, Applications, vol.1, Hemisphere Publ., Washington DC.

Matkovic, M., Cavallini, A., Del Col, D., Rossetto, L., 2009, Experimental study on condensation heat transfer inside a single circular minichannel, IJHMT, vol. 52, 23112323.

Menter, F.R., 1994, Two-Equation EddyViscosity Turbulence Models for Engineering Applications. AIAA J., 32(8), 1598-1605.

Muzaferija, S., Peric, M., Sames, P., Schellin, T., 1998, A two-fluid Navier-Stokes solver to simulate water entry. Proc. 22nd Symposium on Naval Hydrodynamics, 277289, Washington DC.

Nebuloni, S., Thome, J.R., 2010, Numerical modeling of laminar annular film condensation for different channel shapes, IJHMT, vol. 53, 2615-2627.

NIST, 2007, National Institute of Standard and Technology, Refprop8, Boulder Colorado.

Van Leer, B., 1979. Toward the ultimate conservative difference scheme. IV. A second order sequel to Godunov's method. Journal of Computational Physics, vol. 32, 101-136.

Wang, H.S., Rose, J.W., 2006, Film condensation in horizontal microchannels: Effect of channel shape, Int. Journal of Thermal Science, vol. 45, 1205-1212.

Wilcox, D.C., 1998, Turbulence Modeling for CFD. DCW Industries, Inc., La Cañada, California, USA. 